\title{
Method for determining of the coatings thermophysical properties formed by the microarc oxidation
}

\author{
Natalya Dudareva ${ }^{1, *}$, Rida Gallyamova ${ }^{1}$, and Alexander Kruglov ${ }^{2}$ \\ ${ }^{1}$ Ufa State Aviation Technical University, 450008, Ufa, Russia \\ ${ }^{2}$ National Research Nuclear University MEPhI, 115409, Moscow, Russia
}

\begin{abstract}
In this work are determined the thermophysical parameters (coefficient of thermal conductivity, thermal diffusivity and heat capacity) of a coating formed by the microarc oxidation (MAO) method on an aluminum alloy AK12D. A method for determining the thermal properties of the MAO layers was developed and verified. The technique is based on measuring the thermal conductivity of the layer by pulsed laser heating and calculating its heat capacity and density based on the data of layer-by-layer phase analysis taking into account the volume porosity. The method allows to calculate the thermophysical parameters whose values differ from the experimental no more than $2.2 \%$ in thermal conductivity and no more than $7.0 \%$ for heat capacity. In accordance with the proposed method, it was found that the MAO layer on AK12D alloy has a low thermal conductivity of $\sim 1.57 \mathrm{~W} /(\mathrm{m} \cdot \mathrm{K})$ at $100{ }^{\circ} \mathrm{C}$.
\end{abstract}

\section{Introduction}

The technology of microarc oxidation (MAO) is becoming increasingly popular in industry at this time $[1,2]$. This method allows the formation of modified surface layers with a unique combination of properties: high wear resistance, corrosion resistance and heat resistance $[3,4]$. The wear resistance and corrosion resistance of MAO coatings are well studied nowadays. Meanwhile, the amount of data on the thermophysical properties of these coatings is insufficient. Such situation prevents the widespread use of MAO technology in power engineering, as it does not allow one to evaluate the effect of the coating on the thermal state of parts.

The investigation of the thermophysical properties of the MAO layers is a difficult methodical task, since these coatings are ceramics with an inhomogeneous and complex chemical composition. Such coatings are characterized by high porosity and uneven thickness [2, 4]. For this reason, the total number of works about the measurement of the thermophysical properties of MAO layers is extremely small. Only a few papers present a description of studies of the thermal conductivity of the MAO layer formed on the deformable alloy 6082 in a silicate-alkaline electrolyte [5-7]. The authors of these articles found that the thermal conductivity of the MAO layer is $\lambda=1.64 \pm 0.4 \mathrm{~W} /(\mathrm{m} \cdot \mathrm{K})[5,6]$, and if

\footnotetext{
*Corresponding author: natalia_jd@mail.ru
} 
the oxide layer is saturated with mullite, so $\lambda=0.5 \pm 0.2 \mathrm{~W} /(\mathrm{m} \cdot \mathrm{K})$ [7]. These measurements were carried out using the stationary heat flux method, which does not make it possible to determine the thermal conductivity of the coating with high correctness. Obviously, there is a need for a method for determining the thermophysical properties of MAO layers with larger accuracy.

It is known that the thermophysical properties of materials are directly related to their structure and chemical (phase) composition [8]. Therefore, the aim of this work is the development and verification of a method for determining the thermophysical properties of MAO layers based on their structure and chemical composition.

\section{Description of the method for determining the thermal properties}

\subsection{Determination of the thermal conductivity coefficient}

The most important thermophysical properties of thermal barrier coatings are heat capacity, thermal diffusivity and thermal conductivity. The thermal conductivity coefficient is related to two other properties by a known dependence [9]:

$$
\lambda=a \cdot C_{p} \cdot \rho
$$

where $\lambda$ is coefficient of thermal conductivity of the material, $\mathrm{W} /(\mathrm{m} \cdot \mathrm{K}) ; a$ - thermal diffusivity, $\mathrm{m}^{2} / \mathrm{s} ; C_{p}$ - heat capacity, $\mathrm{kJ} /(\mathrm{kg} \cdot \mathrm{K}) ; \rho$ is the density, $\mathrm{kg} / \mathrm{m}^{3}$.

To determine the thermal conductivity coefficient, it is necessary to determine the thermal diffusivity $(a)$, heat capacity $\left(C_{p}\right)$ and coating density $(\rho)$ with high accuracy (eq.1).

\subsection{Determination of the thermal diffusivity}

A pulsed laser heating method or a Parker method is the most accurate method for determining thermal diffusivity nowadays [10]. The presented technique proposes to use this method for the study of MAO layers.

\subsection{Determination of the density}

The geometric method for determining the density of MAO layers leads to the appearance of significant mistakes. Therefore, the determination of the coating density by proposed technique is based on the phase mixing rule [11] and information on the phase composition of the coating and its porosity. The density value is calculated by the equation:

$$
\rho_{\text {MAOcalc }}=\left(1-V_{\text {pore }}\right) \cdot \Sigma\left(V_{N} \cdot \rho_{N}\right)
$$

where $V_{N}$ is the volume fraction of the $N$ phase in the MAO layer; $V_{\text {pore }}$ - the volume fraction of pores; $\rho_{N}$ is the density of the corresponding phase, $\mathrm{kg} / \mathrm{m}^{3}$.

Reference data for the densities of the individual phases present in the coating $\left(\rho_{N}\right)$ must be used in calculations under equation (2).

The phase composition of the coating is determined in layers by X-ray phase analysis (XRD). The porosity of the MAO layer is determined by applying a square grid to the image of the transverse section of the coating obtained using a scanning electron microscope (SEM) [12]. 


\subsection{Determination of the heat capacity}

The MAO layers are a porous mixture consisting of several chemical compounds that do not enter into a chemical reaction with each other. Therefore, the calculation of heat capacity by this method can also be carried out according to the rule of the mixture [13]:

$$
C_{p M A O \text { calc }}=\left(1-V_{\text {pore }}\right) \cdot \Sigma\left(V_{N} \cdot \rho_{N} \cdot C_{p N}\right) / \rho_{\text {MAOcalc }}
$$

where $C_{p M A O \text { calc }}$ is the estimated specific heat capacity of the MAO layer, $\mathrm{kJ} /(\mathrm{kg} \cdot \mathrm{K}) ; V_{N}$ is the volume fraction of the $N$ phase in the MAO layer; $V_{\text {pore }}$ - the volume fraction of pores in the coating; $C_{p N}$ is the specific heat capacity of the $N$ phase, $\mathrm{kJ} /(\mathrm{kg} \cdot \mathrm{K}) ; \rho_{N}$ is the density of the $N$ phase, $\mathrm{kg} / \mathrm{m}^{3} ; \rho_{\text {MAOcalc }}$ is the density of the MAO layer, calculated by the equation (2).

The heat capacities for individual coating phases $\left(C_{p N}\right)$ at various temperatures are calculated using empirical formulas known from the scientific and reference literature.

\section{Approbation of the method}

\subsection{Formation of the MAO layer on the sample}

The method was tested on a sample of aluminum alloy AK12D [14]. The sample was a disk with a diameter of $68 \mathrm{~mm}$ and a thickness of $10 \mathrm{~mm}$. On this sample MAO layer was formed. The MAO process was carried out in a silicate-alkaline electrolyte containing $\mathrm{Na}_{2} \mathrm{SiO}_{3}(2.5 \mathrm{~g} / \mathrm{l})$ and $\mathrm{KOH}(2.5 \mathrm{~g} / \mathrm{l})$. The electrical parameters of the process were as follows: ratio of anode and cathode currents $I a / I k=1$, average current density $j=13 \pm 2 \mathrm{~A} / \mathrm{dm}^{2}$, pulse frequency $50 \mathrm{~Hz}$. The processing time was 1.5 hours.

The thickness of the MAO layer was measured from cross-sectional images obtained with a scanning electron microscope JEOL JSM 6390 (SEM) at x500 magnification in the backscattered electron mode using the Scale program. The thickness value was $\mathrm{h}=154.1 \pm 3.7 \mu \mathrm{m}$ (Fig. 1).

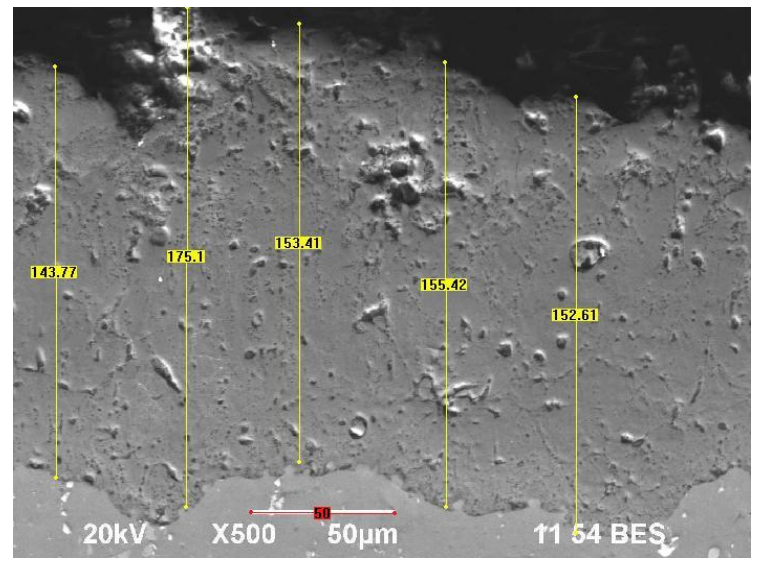

Fig. 1. MAO layer on a sample of AK12D alloy.

\subsection{Study of the phase composition and porosity of the MAO layer}

The phase composition of the MAO layer was determined at room temperature using a Rigaku Ultima IV X-ray diffractometer in $\mathrm{Cu}-\mathrm{K} \alpha$ radiation in the angle range $2 \theta=15-100^{\circ}$. The wavelength was $\lambda=1.540562 \AA$, and the shooting step $0.02 \circ$. The diffraction pattern was processed using the "Match! 3", based on the Rietveld method [15, 16]. To increase the 
accuracy of the results, the phase composition of the oxide layer was determined layer by layer, gradually removing layers $16-17 \mu \mathrm{m}$ thick. The thickness of these information layers in the X-ray phase analysis of aluminum oxides was calculated and the result is $16 \mu \mathrm{m}$ [17].

Before the quantitative phase analysis of the MAO-layer, the X-ray profiles were processed in "Match! 3". The convergence of the profiles was estimated by the profile uncertainty factor $(R \mathrm{p})$ [16]. When analyzing the MAO layer, the following phases were distinguished: $\alpha-\mathrm{Al}_{2} \mathrm{O}_{3}, \gamma-\mathrm{Al}_{2} \mathrm{O}_{3}, 3 \mathrm{Al}_{2} \mathrm{O}_{3} \cdot 2 \mathrm{SiO}_{2}$ (mullite), $\mathrm{Al}_{2} \mathrm{SiO}_{5}$ (sillimanite), and $\mathrm{SiO}_{2}$ $[2,18]$. The results of the layer-by-layer quantitative phase composition are presented in Fig. 2 and Tab. 1.

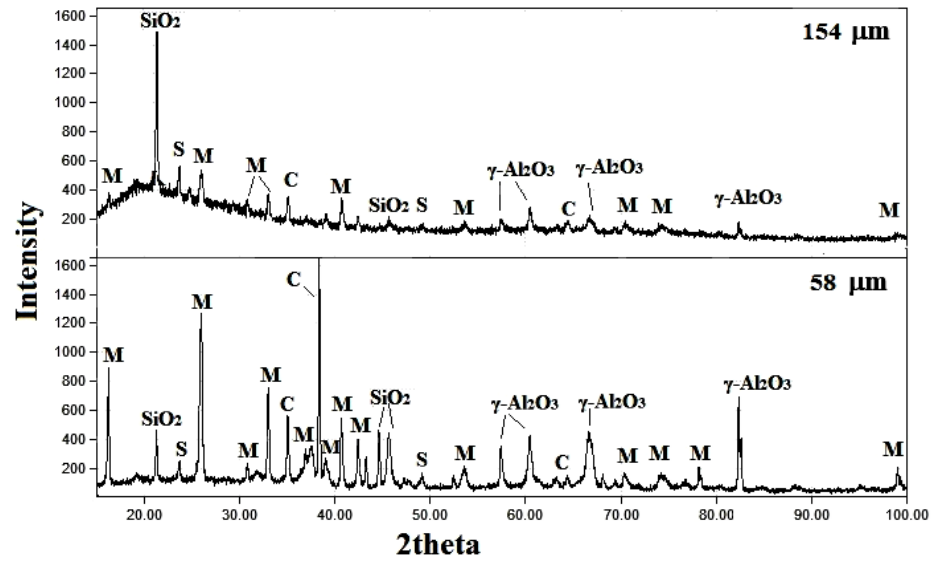

Fig. 2. The phase composition of the MAO layer on $A K 12 D$; Key: $\mathrm{C}-$ corundum $\alpha-\mathrm{Al}_{2} \mathrm{O}_{3}, \mathrm{M}-$ mullite $3 \mathrm{Al}_{2} \mathrm{O}_{3} \cdot 2 \mathrm{SiO}_{2}, \mathrm{~S}$ - sillimanite $\mathrm{Al}_{2} \mathrm{SiO}_{5}$.

Table 1. The results of X-ray phase analysis of the MAO layer.

\begin{tabular}{|c|c|c|c|c|c|c|c|}
\hline \multirow{2}{*}{$\begin{array}{l}\text { The distance } \\
\text { from } \begin{array}{c}R_{p}, \\
\text { the }\end{array}\end{array}$} & \multicolumn{6}{|c|}{ Phase oxide layer, \% } & $\begin{array}{c}\text { Porosity, } \\
V_{\text {pore }} \%\end{array}$ \\
\cline { 3 - 8 } & $\alpha-\mathrm{Al}_{2} \mathrm{O}_{3}$ & $\gamma-\mathrm{Al}_{2} \mathrm{O}_{3}$ & $3 \mathrm{Al}_{2} \mathrm{O}_{3} \cdot 2 \mathrm{SiO}_{2}$ & $\mathrm{Al}_{2} \mathrm{SiO}_{5}$ & $\mathrm{SiO}_{2}$ & \\
\hline 154 & 6.3 & 7.4 & 6.0 & 43.3 & 0.0 & 43.3 & \\
\hline 135 & 7.7 & 5.4 & 9.0 & 41.2 & 24.6 & 19.8 & \multirow{2}{*}{$13.1 \pm 1.6$} \\
\hline 101 & 9.5 & 7.2 & 9.7 & 53.5 & 24.8 & 4.9 & \\
\hline 88 & 7.7 & 12.5 & 2.2 & 43.3 & 39.1 & 3.0 & \\
\hline 58 & 17.8 & 8.4 & 15.7 & 66.8 & 0.0 & 9.1 & \\
\hline Average value & - & 8.2 & 8.5 & 49.6 & 17.7 & 16.0 & \\
\hline
\end{tabular}

\subsection{Calculation of the density of the MAO layer}

The coating density was calculated on the basis of X-ray phase analysis data (Table 1), according to the eq. (2). For such calculations, reference density values for individual coating phases were used (Tab. 2). As a result, the calculated density of the MAO layer was $\rho_{\text {MAO calc }}=2721 \pm 50 \mathrm{~kg} / \mathrm{m}^{3}$.

Table 2. Density of individual phases [19-21].

\begin{tabular}{|c|c|c|c|c|}
\hline \multicolumn{5}{|c|}{ Density, kg/m3 } \\
\hline$\alpha-\mathrm{Al}_{2} \mathrm{O}_{3}$ & $\gamma-\mathrm{Al}_{2} \mathrm{O}_{3}$ & $\begin{array}{c}3 \mathrm{Al}_{2} \mathrm{O}_{3} \cdot 2 \mathrm{SiO}_{2} \\
\text { (mullite) }\end{array}$ & $\begin{array}{c}\mathrm{Al}_{2} \mathrm{SiO}_{5} \\
\text { (sillimanite) }\end{array}$ & $\mathrm{SiO}_{2}$ \\
\hline 3960 & 3200 & 3200 & 3230 & 2340 \\
\hline
\end{tabular}




\subsection{Calculation of the heat capacity of the MAO layer}

The calculation of the heat capacity of the layer was carried out by the eq. (3). The heat capacities for individual phases at various temperatures were calculated by empirical formulas. For the $\mathrm{Al}_{2} \mathrm{O}_{3}$ phase $\left(\alpha-\mathrm{Al}_{2} \mathrm{O}_{3}\right.$ and $\left.\gamma-\mathrm{Al}_{2} \mathrm{O}_{3}\right)$, the formula for calculating the molar heat capacity [13] was used:

$$
C \mu_{p \mathrm{Al} 2 \mathrm{O} 3}=114.56+12.89 \cdot 10^{-3} \cdot T-34.31 \cdot 10^{5} \cdot T^{-2}
$$

where $T$ is the temperature, $\mathrm{K}$.

The molar heat capacity of sillimanite was calculated by the equation [22]:

$$
C \mu_{p \text { silimanite }}=372.11-74.29 \cdot 10^{-3} \cdot T+23.56 \cdot 10^{-6} \cdot T^{-2}-2.4 \cdot 10^{-9} \cdot T^{-3}-3943.4 \cdot T^{-0.5}
$$

The specific mass heat capacity of mullite was calculated by the equation [22]:

$$
C_{p \text { mullite }}=286.68+139.01 \cdot \ln (T)
$$

The heat capacity of the $\mathrm{SiO}_{2}$ phase was calculated using the equation [23]:

$$
C_{p S i O 2}=17.91+88.12 \cdot 10^{-3} \cdot T
$$

Heat capacity calculations were carried out for temperatures of 50,100, 150, and $200{ }^{\circ} \mathrm{C}$. All obtained values were reduced to specific mass heat capacity. The results of the calculation of the heat capacity of individual phases according to the formulas (4)-(7) and the heat capacity of the MAO layer calculated by the eq. (3) are shown in Tab. 3.

Table 3. The calculated heat capacities of the individual phases and the MAO layer.

\begin{tabular}{|c|c|l|l|c|c|}
\hline Temperature, ${ }^{\circ} \mathrm{C}$ & \multicolumn{5}{|c|}{ Heat capacity, $C_{p}, \mathrm{~kJ} /(\mathrm{kg} \cdot \mathrm{K})$} \\
\cline { 2 - 6 } & $\mathrm{Al}_{2} \mathrm{O}_{3}$ & $3 \mathrm{Al}_{2} \mathrm{O}_{3} \cdot 2 \mathrm{SiO}_{2}$ & $\mathrm{Al}_{2} \mathrm{SiO}_{5}$ & $\mathrm{SiO}_{2}$ & $C_{p \text { MAOcalc }}$ \\
\hline 50 & 0.842 & 0.830 & 0.809 & 0.771 & 0.821 \\
\hline 100 & 0.929 & 0.927 & 0.885 & 0.845 & 0.910 \\
\hline 150 & 0.989 & 0.983 & 0.944 & 0.918 & 0.969 \\
\hline 200 & 1.033 & 1.023 & 0.992 & 0.991 & 1.015 \\
\hline
\end{tabular}

\subsection{Determination of the thermal diffusivity}

The thermal diffusivity was determined using a NETZSCH LFA 457 MicroFlash pulsed laser heating system [24]. In the first part of the experiment, the thermophysical properties of the AK12D alloy were determined by pulsed laser heating: thermal diffusivity, heat capacity, and thermal conductivity.

The thermophysical properties of the AK12D alloy were determined on a sample without coating at the beginning of the experiment. The values of thermal diffusivity, heat capacity, the coefficient of linear thermal expansion and thermal conductivity were measured.

The errors of the measured values of thermal diffusivity was determined on the basis of metrological characteristics of the installation and test measurements and amounted to $\Delta a / a \leq 5 \%$. All studies were carried out in the temperature range of $50-400{ }^{\circ} \mathrm{C}$. The result was the dependence of thermal diffusivity of the oxide layer from a temperature $\left(t,{ }^{\circ} \mathrm{C}\right)$ :

$$
a_{M A O}=1.198 \cdot t^{-0.1385} \cdot 10^{-6}
$$




\subsection{Determination of the thermal conductivity}

The thermal conductivity values of the MAO layer were calculated using the eq. (1) for different temperatures (Table 4).

Table 4. The calculated thermal conductivity of the MAO layer

\begin{tabular}{|c|c|c|c|c|}
\hline \multirow{2}{*}{$\begin{array}{l}\text { Thermal conductivity, } \\
\mathrm{W} /(\mathrm{m} \cdot \mathrm{K})\end{array}$} & 50 & 100 & 150 & 200 \\
\cline { 2 - 5 } & $1,56 \pm 0,28$ & $1,57 \pm 0,28$ & $1,58 \pm 0,28$ & $1,59 \pm 0,29$ \\
\hline
\end{tabular}

Then, the equation of the effect of temperature on the thermal conductivity of the MAO layer was obtained:

$$
\lambda_{\text {MAOAalc }}=0.0002 \cdot t+1.547
$$

\section{Verification of the method}

Verification of the proposed methodology was based on experimental determination of calculated parameters (the heat capacity and the density).

The density of the MAO layer was determined by the geometric method. The density of aluminum alloy was measured with a special experiment. The samples were weighted using a Mettler Toledo XPE 26 microbalance, to $\pm 2.5 \mu \mathrm{g}$ precision. The geometrical sizes of the samples were measured using a LINKS digital measuring instrument with an accuracy of $\pm 0.03 \mathrm{~mm}$. Previously received value $\mathrm{h}=$ thickness of $154.1 \pm 3.7 \mathrm{~mm}$ were used in the calculations.

The heat capacity was determined on a NETZSCH DSC 404F3 differential scanning calorimeter in the temperature range $50-200{ }^{\circ} \mathrm{C}$ [25]. The measurements were carried out on a powder from the MAO layer, previously removed from the sample by mechanical means. The mass of the powder was $33.454 \mathrm{mg}$. A sapphire standard of heat capacity was used as a comparison sample. When measuring, was used the typical heating program used to measure the heat capacity $(C p)$ : isothermal exposure of the sample at $32{ }^{\circ} \mathrm{C}$ for $10 \mathrm{~min}$; heating rate $20^{\circ} \mathrm{C} / \mathrm{min}$ to $200{ }^{\circ} \mathrm{C}$; isothermal exposure at $200{ }^{\circ} \mathrm{C}-3 \mathrm{~min}$. The results were processed using the NETZSCH Proteus software.

\section{Results and discussion}

The measured density of AK12D aluminum alloy was $\rho_{\mathrm{Al}}=2679 \pm 4 \mathrm{~kg} / \mathrm{m}^{3}$, and the density of the MAO layer was $\rho_{M A O}=2659 \pm 565 \mathrm{~kg} / \mathrm{m}^{3}$. Comparing the density values obtained by calculation and experimentally, we can see that the average calculated value $\left(\rho_{\text {MAOcalc }}=\right.$ $2721 \pm 50 \mathrm{~kg} / \mathrm{m}^{3}$ ) differs from the measured value by $2.3 \%$ and is in the range of its error.

The heat capacity values of the MAO layer in the temperature range $50-200{ }^{\circ} \mathrm{C}$ were obtained as an array of data, which are graphically shown in Fig. 3. The effect of temperature on the specific mass heat capacity of the coating was established after processing these data [26]:

$$
C_{p M A O}=830.82+1.0289 \cdot t-0.0013 \cdot t^{2}
$$

where $t$ is temperature, ${ }^{\circ} \mathrm{C}$.

Comparison of the calculated and measured values of the heat capacity showed that the maximum difference in values does not exceed $7.0 \%$ (Fig. 3) and an average of $3.0 \%$. 


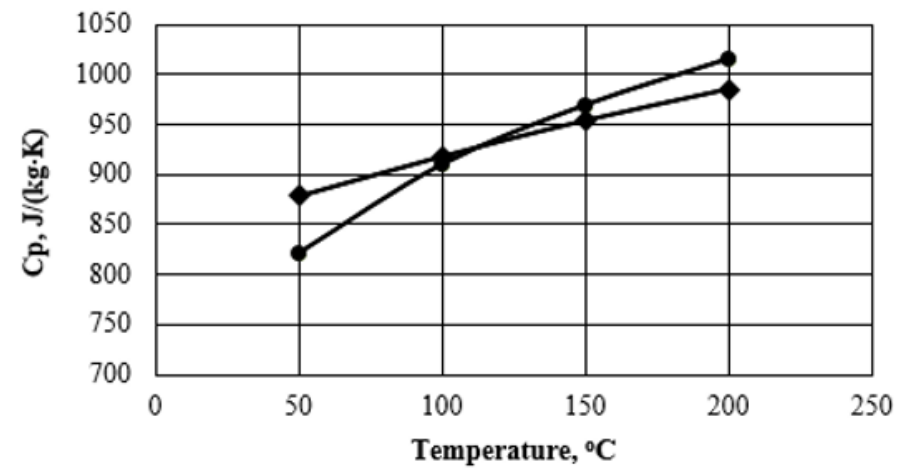

Fig. 3. Heat capacity of the MAO layer on AK12D alloy: designations: - - calculated values; measured values.

The experimental equation of the thermal conductivity coefficient obtained using the measured values of the density and heat capacity of the MAO layer [26]:

$$
\lambda_{\text {MAOexp }}=0.0002 \cdot t+1.513
$$

The difference between the calculated value and the measured value of the thermal conductivity coefficient was $2.2 \%$ (Fig. 4). The relative error for the calculated values of the coefficient of thermal conductivity $\left(\lambda_{\text {MAOcalc }}\right)$ was $7 \%$, and for the measured $\left(\lambda_{\text {MAOexp }}\right)$ was $22 \%$.

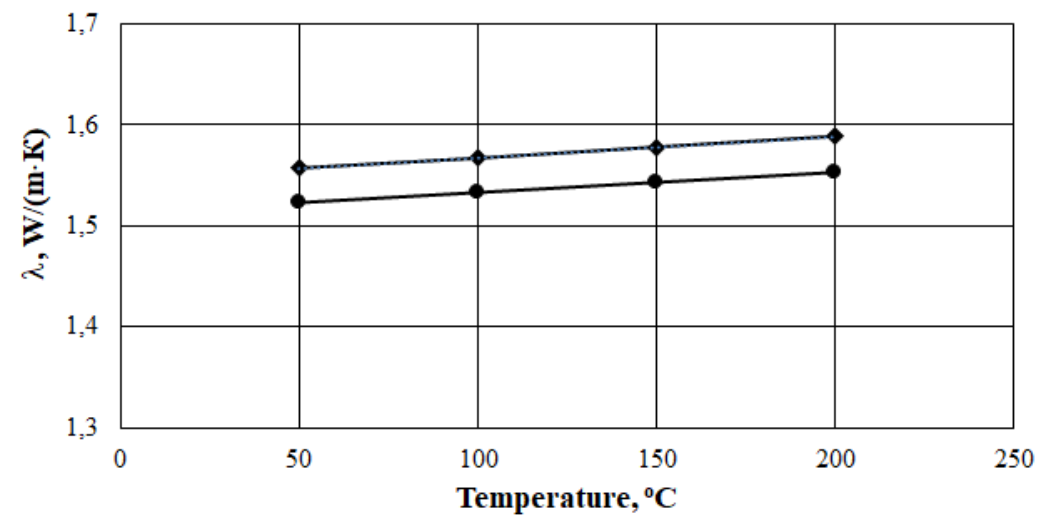

Fig. 4. Thermal conductivity coefficient of the MAO layer on AK12D alloy; designations: measured values; - calculated values.

A comparative analysis of experimental and calculated data and the obtained equations allowed to draw a conclusion about the convergence of the results and the practical significance of the developed method.

\section{Conclusion}

The proposed method for calculating the thermophysical parameters of the MAO layers is of practical importance, since its verification showed high convergence with experimental results. The discrepancy between the calculated and experimental values of the thermal conductivity is $\sim 2 \%$, and for the heat capacity it does not exceed $7 \%$. Thus, it is shown 
that the heat capacity values calculated by the additivity rule and the density values calculated on the basis of the composition and structure of the coating correlate with the results of heat capacity and density measurements well. Also, the proposed method allows to increase the accuracy of determining the thermophysical parameters of the MAO layer.

\section{References}

1. R.O. Hussein, D.O. Northwood and X. Nie, Mater. Sci. and Appl., 5, 124-139 (2014)

2. A.L. Yerokhin, A.A. Voevodin and et., Surf. Coat. Technol. 110 (1998)

3. N.Y. Dudareva, M.M. Abramova, R.V. Kalschikov, Mat. Sci. Forum Sub. 870, 83-89 (2016)

4. A.V. Kolomeychenko, N.S. Chernyshov, N.V. Titov and V.N. Logachev. Surf. Eng. and Appl. Electrochem. 4, 322-326 (2017)

5. J.A. Curran, T.W. Clyne, Surf. Coat. Technol. 183, 177-183 (2005)

6. J.A. Curran, Thermal and mechanical properties of plasma electrolytic oxide coatings (University of Cambridge, Cambridge, 2006)

7. J.A. Curran, H. Kalkancı, Yu. Magurova, T.W. Clyne, Surf. Coat. Technol. 201, 86838687 (2007)

8. C. Godart, A.P. Gonçalves, E.B. Lopes, B. Villeroy, Role of Structures on Thermal Conductivity in Thermoelectric Materials, (Springer, 2009)

9. J.H. Lienhard IV, J.H. Lienhard V, A Heat Transfer Textbook (Cambridge, 2017)

10. W.J. Parker, R.J. Jenkins, C.P. Butler, G.L. Abbott. J. of Appl. Phys. 32, 1679-1684 (1961)

11. K.K. Chawla, Revista Brasileira de Fisica. 3, 413-418 (1974)

12. S.A. Saltykov, Stereometric metallography (Metallurgy, Moscow, 1970)

13. S.D. Beskov, Techno-chemical calculations (Higher school, Moscow, 1962)

14. N.Y. Dudareva, M.M. Abramova, Protec. Met. Phys. Chem. Surf. 1, 128-132 (2016)

15. H.M. Rietveld, A Retrospection. Z. Kristallogr. 225, 545-547 (2010)

16. Match! Phase Identification from Powder Diffraction: http://www.crystalimpact.com/match (access 14.03.2019)

17. L.I Mirkin, Handbook of X-ray diffraction analysis of polycrystals (Moscow, 1961)

18. N.Yu. Dudareva, A.B. Kruglov, R.F. Gallyamova, Sol. State Phenom. 284, 1235-1241 (2018)

19. J.F. Shackelford, R.H. Doremus, Ceramic and Glass Materials. Structure, Properties and Processing (Springer, 2008)

20. B.P. Nikolsky, Handbook of chemist. Basic properties of inorganic and organic compounds (Chemistry, Leningrad-Moscow, 1964)

21. Sillimanite: http://www. kristallov.net (access 09.02.2019)

22. G.V. Lyamina, and et. Chemical Thermodynamics (Tomsk, 2007)

23. E.A. Melekhova, P.I. Dorogokupets, The electronic J. Investigated in Russia. (2002)

24. Netzsch. LFA 457 MicroFlash: http://www.netzsch.com (access 08.04.2019)

25. DSC 404 F1 Pegasus: https://www.netzsch-thermal-analysis.com (access 25.04.2019)

26. N.Yu. Dudareva, P.V. Ivashin, A.B. Kruglov. MATEC Web of Conferences, 129, 02015 (2017) 